Book Reviews

\title{
A Welcome and Introduction
}

DARREN STANLEY

University of Windsor (Canada)

First, I must thank Kris, a fellow complexivist, for his kind words of welcome. To be sure, I must thank him for his hard work to bring to our collective attention such a wide range of very interesting texts and works that mark and speak to the field of complexity studies. Indeed, the whole editorial team deserves our thanks for bringing to the "horizon of possibilities" new and inspirational ways to "think, act, and do research differently." I am most humbled to be asked to continue in the foot steps of my colleagues; I look forward to bringing reviews of new and more classic texts into the light for future Complicity readers.

I look forward to working with the new editorial team. They are individuals whom I respect greatly. And, undoubtedly, they will continue in the tradition of complexity studies to seek out and bring readers a diverse array of texts and work that may serve to highlight the promises that the field seems to offer so many. In a similar manner, I hope that the forthcoming book reviews will also highlight the same rich, diverse possibilities for complexity interpretations of a broad range of educational matters, concerns, and interests.

I look forward to your suggestions for future book reviews and anticipate sharing with you many more books that undoubtedly will require reviewers! The next three years, I am sure, will be just as exciting as the last. 